\title{
ENSINO DE LÍNGUAS COM REFUGIADOS: IMPLICAÇÕES ÉTICAS, POLÍTICAS E CONCEITUAIS EM TEMPOS DE BIOPODER
}

\author{
Poliana Coeli Costa Arantes \\ Bruno Deusdará \\ Décio Rocha
}

\begin{abstract}
RESUMO
Neste artigo, discutem-se implicações éticas e políticas do trabalho de ensino de língua portuguesa dirigido a sujeitos refugiados no Rio de Janeiro, assumindo-se uma abordagem enunciativa da linguagem, que toma por base práticas discursivas assentadas em uma perspectiva dialógica. Nesse contexto, será destacada a dimensão intercultural que preside à dinâmica de produçẫo de materiais didáticos.
\end{abstract}

PALAVRAS-CHAVE: refugiado; política linguística para o ensino de língua portuguesa; produção de material didático.

A ambição suprema do biopoder consiste em produzir em um corpo humano a separação absoluta entre o ser vivo e o ser que fala, entre a zoé e o bios, o não homem e o homem: a sobrevivência.

Giorgio Agamben

Considerações iniciais

N

o presente artigo, discutimos implicaçóes éticas, políticas e conceituais envolvidas em ação de política linguística a que nos vimos convocados, quando aceitamos a encomenda de trabalho de acolhida a refugiados, 
por meio de representantes da Cáritas/RJ, que coordenam o curso de português para esta população de solicitantes de refúgio e refugiados.

Se optamos por discutir as especificidades do trabalho com refugiados, recusando a pretensão de que se pudesse considerá-los como um grupo específico de "estrangeiros" para os quais bastariam algumas adaptações nos métodos adotados, fundamentamos esse impasse ético-político nas análises dos efeitos das tecnologias e cálculos do poder na contemporaneidade. A título de ilustração do que ora sustentamos, recorremos a Homo Sacer, obra na qual G. Agamben afirma que a distinção sugerida na "Declaração universal de direitos do homem e do cidadão" assinala a crise da ideia moderna assentada na correspondência entre indivíduo e cidadão. Nesses termos, "as declaraçóes dos direitos representam aquela figura original da inscrição da vida natural na ordem jurídico-política do Estado-nação" (AGAMBEN, 2007, p. 134).

De certo modo, essa tese propõe diálogos com a reflexão foucaultiana a respeito do biopoder. Para Foucault (2002), a transição entre o poder soberano como forma de organização prioritária até o século XVIII e o biopoder se institui promovendo deslocamentos que partem de um exercício que se realizava numa territorialidade e se apropriava do resultado da produção agrícola até um interesse pelo corpo vivo, com a combinação de tecnologias de poder que ora se exercem sobre o corpo-espécie, ora sobre o corpo individual.

Desse modo, passou-se do direito do soberano sobre a vida de seus súditos - era em nome do rei que se deixava viver ou se fazia morrer - ao biopoder, em função do qual os investimentos das técnicas e dos cálculos do poder sobre o corpo vivo operam uma inversão fundamental, constituindo-se agora pela lógica de "fazer viver, deixar morrer". Desse modo, teria entrado em cena, por meio de técnicas muito diversas, um exercício de poder que

“centrou-se no corpo-espécie, no corpo transpassado pela mecânica do ser vivo e como suporte dos processos biológicos: a proliferação, os nascimentos e a mortalidade, o nível de saúde, a duração da vida, a longevidade, com todas as condiçôes que podem fazê-los variar; tais processos sáo assumidos mediante toda uma série de intervençôes e controles reguladores" (FOUCAULT, 1980, p. 131). 
Compreendendo a crise humanitária a que estáo submetidos os refugiados não como exceção, mas como regra dos modos de funcionamento do poder nos estados nacionais na atualidade, entendemos ser necessário assimilar suas urgências, necessidades, especificidades como um pedido que interroga nossas formas de organização do saber, nossas implicações éticas com o público ao qual nosso trabalho se dirige.

Assimilando essas questôes, a construção da problematização proposta por esta reflexão nos permite não apenas apresentar as contribuiçóes que podemos oferecer ao público de refugiados, mas principalmente sustentar de que modo esse movimento de trabalho indaga a organizaçáo institucional que estabelece fronteiras sempre frágeis entre i) saberes dos especialistas da linguagem e dos falantes de uma língua; ii) formação acadêmica e atuação profissional; iii) práticas extensionistas e atividade de pesquisa.

\section{Contextualizando a ação: caracterização da demanda e do campo de intervenção}

Inicialmente, a solicitação centrou-se em dois aspectos: o primeiro deles residia numa crítica aos encaminhamentos que o material didático sugeria para as aulas de língua portuguesa, excessivamente pautado por exercícios de natureza estrutural; o segundo aspecto já apontava um eixo propositivo, indicando que uma recente alteração no perfil do grupo de refugiados exigia discussão a respeito de temáticas como gênero, infância, convívio familiar, entre outras.

De fato, é preciso compreender que os dois eixos anteriormente explicitados nos davam pistas de uma crítica e, simultaneamente, de uma sugestão propositiva para um trabalho de intervenção cujo desenho náo se encontra previamente configurado. Como já tivemos a oportunidade de sustentar, não se trata apenas de um público específico para o que já se realiza no âmbito dos cursos de português como língua estrangeira, mas uma prática de ensino de línguas em contexto diverso (ARANTES; DEUSDARÁ, 2015). É a própria natureza da motivação para a aprendizagem da língua e sua inserçáo em um novo contexto que se encontra em evidência, já que se trata de pessoas cujos direitos básicos à vida digna se encontram gravemente ameaçados. Nesse sentido, a dimensão do vínculo que se passa a estabelecer não pode ser de modo 
algum apagado, sob risco de comprometimento do próprio processo de acolhimento, que passa não apenas pela necessidade de inserção na vida social e no mercado de trabalho, mas também de dispor dos bens culturais e de direito à livre circulação na cidade de acolhimento.

Dessa forma, ao lado do atendimento à referida solicitação, em seus desdobramentos concretos, consideramos bastante produtivo problematizar de que modo o próprio processo de construção de alternativas de trabalho interroga as especialidades, as fronteiras disciplinares, as práticas profissionais nas quais nos encontramos inseridos a partir do contato com o outro, atuando na formação de professores de línguas materna e estrangeiras.

Sendo assim, vale destacar que a comanda feita inicialmente pela coordenação pedagógica da Cáritas/RJ, pretendia que atuássemos na supervisão e na compilação de materiais didáticos para uso no curso de português. No entanto, essa comanda inicial foi transformada e adaptada na medida em que o contato com os refugiados e com suas solicitaçóes de aprendizagem foi surgindo em nosso levantamento, o que nos levou a investir em um caminho de elaboração de materiais específicos para o grupo de refugiados, criando assim uma área de abordagem bastante diferente daquela que investe no ensino de língua portuguesa para estrangeiros.

Com inspiração nos referenciais da análise institucional, compreendemos que uma encomenda de trabalho comporta sentidos para além daqueles que se explicitam nos primeiros contatos entre o grupo solicitante e a equipe que se formará para atender à solicitação de intervenção. Assim, passa-se da comanda (formulada inicialmente) à explicitaçáo de uma demanda (latente). Desse ponto de vista, intervençáo se caracteriza por "produzir evidências que visibiliz[ass] em o jogo de interesses e de poder encontrados no campo de investigação" (PASSOS; BARROS, 2000, p. 73).

Nesse processo, a importância da escuta inicial reside em permitir identificar queixas que motivam a solicitação, críticas ao que se realiza, expectativas de que haja mudanças em certos aspectos. Nessa etapa preliminar, promove-se o encontro entre perspectivas distintas, oriundas de universos de sentidos e práticas não coincidentes, de tal modo que não se deve perder de vista a necessidade de considerar legítimo o ponto de vista apresentado, mesmo que guarde distâncias inevitáveis - e, até mesmo, necessárias - no que tange aos campos de atuação em contato. No caso em discussão, esse distanciamento 
se explicitou de modo mais evidente, a título de exemplo, nas expectativas relativas ao ritmo de trabalho: a acolhida aos refugiados exige uma dinâmica complexa de açôes em um intervalo curto de tempo, enquanto a compreensão dos processos em jogo e dos diferentes modos de responder às solicitaçóes nos implica em escolhas conceituais e profissionais que demandam tempo de reflexão.

A partir desse momento preliminar de escuta, é necessário passar a discussóes em grupo no âmbito da equipe de atendimento, para que se coloquem em análise as condiçóes de possibilidade de realização do trabalho de intervenção, procurando compreender de que modo os arranjos institucionais, os saberes e valores estabelecidos são interrogados pela solicitação apresentada.

Essa aproximação em relação ao campo de intervenção requer não apenas um movimento da equipe em direção ao que se caracterizaria como remetendo ao "universo do outro", mas, de igual modo, não deixamos de tocar nas inscrições institucionais a partir das quais somos convocados à ação, colocando em questão inclusive o próprio lugar de especialistas por meio do qual nos chega uma solicitação. Em outras palavras, do ponto de vista da análise institucional, "a aproximação com o campo inclui, sempre, a permanente análise do impacto que as cenas vividas/observadas têm sobre a história do pesquisador e sobre o sistema de poder que legitima o instituído, incluindo aí o próprio lugar de saber e estatuto de poder do 'perito-pesquisador" (PAULON, 2005, p. 23).

\section{Momentos iniciais de aproximação ao campo}

Em 2014, a coordenação de gestão pedagógica da Cáritas/RJ procurou intermediação de docentes lotados nos Departamentos de Educação de Jovens e Adultos, da Faculdade de Educação, de Estudos da Linguagem e de Línguas Anglo-Germânicas, do Instituto de Letras, da Universidade do Estado do Rio de Janeiro, para avaliação dos materiais didáticos utilizados no curso de português. A principal queixa fora o fato de o material não atender às expectativas dos alunos, uma vez que a língua abordada pelos livros didáticos de português como língua estrangeira (PLE) era bastante diferente daquela com a qual se deparavam em situaçóes cotidianas.

Conforme já explicitamos em Arantes e Deusdará (2015, p. 48), a excessiva generalização do estrangeiro indica algo que merece nossa atenção, pelo 
modo a partir do qual supóe um interlocutor descolado das necessidades concretas expressas pelo grupo de refugiados. Essa é uma das motivaçôes para a recusa de que se pudessem considerar as iniciativas relativas às práticas de ensino de línguas com refugiados como parte de um conjunto genérico e difuso de "português para estrangeiros", apagando-se a precariedade do vínculo, neutralizando-se as fragilidades constitutivas dos movimentos de migração forçada.

Movimento semelhante encontramos em levantamentos bibliográficos a respeito dos impasses éticos, políticos e profissionais no trabalho com refugiados, do ponto de vista da psicologia. Nesse sentido, Knobloch (2015) critica as alternativas patologizantes e generalistas circunscritas ao diagnóstico da chamada síndrome de Ulisses. A respeito dessa crítica, a autora indica o seguinte: "Para nós, entender a vivência migratória a partir da categoria da Síndrome de Ulisses leva o migrante a um único lugar possível: o de alguém muito vulnerável que irá desenvolver problemas psicológicos que deverão ser medicalizados" (KNOBLOCH, 2015, p. 171).

De modo análogo, observamos que, embora os livros didáticos adotados se inscrevam no método comunicativo, os exercícios de mecanização de estruturas e itens lexicais ainda são predominantes, bem como o uso do português padrão. A quantidade excessiva de exercícios estruturais nos chamou a atenção, sobretudo por justificar, no prefácio do $\mathrm{LD}^{1}$, que a "aquisição" da língua se concretizaria por meio da fixação de estruturas gramaticais.

Dessa forma, observamos que os materiais destinados ao ensino de LP como língua estrangeira não se organizam a partir de necessidades concretas de diferentes grupos, o foco está em compreender o sistema de regras e suas diversas manifestaçóes, o que se acaba sobrepondo ao papel comunicativo do uso da língua. Além disso, as atividades são semiestruturadas (não há incentivo à produção autônoma dos alunos), descontextualizadas das situaçóes de uso e o que é ainda pior: não dialogam com a memória discursiva dos alunos.

Após a realização dessa análise dos livros didáticos, reunimos a equipe pedagógica da Cáritas, os docentes da UERJ envolvidos no projeto e representantes dos alunos refugiados a fim de darmos início a um levantamento de expectativas com relação à aprendizagem da língua portuguesa, orientado pelas sugestóes dos alunos. As críticas levantadas pelos alunos sobre o trabalho

1 Os livros didáticos adotados àquela época foram: Avenida Brasil I (1991) e Falar, Ler, Escrever Português (1999). 
com os livros didáticos de PLE podem ser resumidas nos seguintes tópicos: i) preponderância de atividades de produção escrita; ii) pouco espaço destinado às variaçôes linguísticas; iii) itens gramaticais pouco aplicáveis a situações de comunicação cotidianas; iv) progressão gramatical incompatível com as necessidades de comunicação imediatas.

Como podemos observar, os tópicos levantados pelos alunos refletem sobre um questionamento em comum: qual a relação da língua aprendida e seu uso? Nesse sentido é que chegamos à conclusão de que deveríamos elaborar os materiais do curso com base nas expectativas de comunicação apresentadas pelos alunos, organizadas em torno de situaçóes comunicativas, tais como: "marcar uma entrevista de emprego pelo telefone", "comprar bilhete de metrô no guichê da estação", "descrever sintomas ao médico", entre outras.

Outro eixo de prática também foi estabelecido por meio da investigação do primeiro tópico, uma vez que a maioria dos alunos é originária de culturas que aprendem e falam línguas autóctones africanas. Assim, a preferência pela oralidade também pode ser observada neste elo cultural.

\section{De que lugar falamos: as ferramentas conceituais}

Uma vez delineada o mais detalhadamente possível a real demanda, compreendemos ser necessário explicitar o lugar de fala em que nos situamos inicialmente, evidenciando as ferramentas conceituais com as quais entendemos ser possível responder ao que nos foi solicitado.

O ponto de partida para a construção de um quadro teórico de base para nossas pesquisas é invariavelmente o de uma aposta em questóes diversas, cujo ponto de interseçáo reside em remeterem a uma mesma problemática enunciativa. Assim, estaremos voltados para um debate compreendendo minimamente o caráter interativo, a organização da linguagem, a produção de textos como prática social, a indissociabilidade de texto e contexto, o primado da intertextualidade, a inscrição dos textos em gêneros discursivos.

A perspectiva discursiva pela qual optamos se caracteriza, desse modo, por remeter minimamente a reflexóes de M. Bakhtin e D. Maingueneau. Com efeito, de Bakhtin retomamos a ideia de responsividade, a qual funciona como axioma que fundamenta duas ideias-chave desenvolvidas pelo autor: i) todo enunciado é compreendido supondo sua relação dialógica com enunciados 
anteriores; ii) a compreensão de qualquer enunciado se dá pela produção de um novo enunciado. Com base em tais princípios, rejeita-se a ideia de que a compreensão se daria fundamentalmente pela decomposição de um enunciado em partes menores - seus elementos linguísticos. O conhecimento das partes que constituem um enunciado, ou seja, sua analisabilidade, estaria, nesses marcos, submetido à depreensão do ato de base que dá sustentação à emergência de um enunciado. E se poderia ainda ressaltar que o conhecimento desses elementos linguísticos só seria possível com base na formulação de enunciados que, por sua vez, suporiam situaçóes concretas nas quais estariam inscritos.

De Bakhtin também podemos retomar a estreita relação verificada entre as ideias de signo e ideologia, formulação que, por motivos óbvios, afasta toda e qualquer possibilidade de uma perspectiva conteudística e instrumental de língua:

Tudo que é ideológico possui um significado e remete a algo situado fora de si mesmo. Em outros termos, tudo que é ideológico é um signo. Sem signos não existe ideologia [...] Converte-se, assim, em signo o objeto físico, o qual, sem deixar de fazer parte da realidade material, passa a refletir e a refratar, numa certa medida, uma outra realidade (BAKHTIN, 2004, p. 31).

Em Maingueneau, localizamos outros conceitos que alimentam a perspectiva enunciativa que sustentamos, com especial ênfase na ideia de primado do interdiscurso e na proposta de uma semântica global, segundo a qual "o modo de elaboração, as circunstâncias da enunciação, o suporte material do texto, etc. não poderiam ser independentes dos temas tratados, do tipo de público, etc." (MAINGUENEAU, 2001, p. 66):

A problemática dos enlaçamentos vem colocar em cena a ausência de exterioridade entre coerçóes enunciativas e práticas institucionais, representando, desta forma, um modo de acesso privilegiado às condiçôes de enunciação dos discursos. É justamente por essa propriedade que possuem os textos, qual seja, a de refletir sua própria enunciaçáo, que os enlaçamentos podem também ser designados como processos de 'reflexividade' 
ou de 'autorreferência', os quais se atualizam na materialidade linguística de formas bastante variadas: as aspas, o discurso indireto livre e os enunciados irônicos são algumas de suas manifestaçôes (ROCHA, 2011, p. 11-12).

Uma outra contribuição de Maingueneau que desempenhará um papel central na formulaçáo de nosso quadro teórico de base reside no conceito de prática discursiva, que diz respeito aos enlaçamentos que se verificam entre a produção de textos e a produção de uma comunidade que, simultaneamente, dá sustentação e é sustentada por esses mesmos textos. O referido conceito nos permite considerar que a aquisição de uma língua - função que se expressa por intermédio da produção de textos - supõe a inscrição do falante em uma comunidade que será responsável por tal produção e ganhará legitimidade por meio desses textos que é capaz de produzir e de fazer circular. Tal circularidade é absolutamente desejável quando lidamos com sujeitos cuja marca central é precisamente a de serem refugiados, situação na qual se explicita de modo contundente a indissociabilidade entre o exercício da língua e o direito - a ser conquistado pelo sujeito - de participação como integrante de grupo(s).

Com Maingueneau (1989, p. 127) podemos ainda explorar a produtividade de um conceito como o de cenografia, tendo em vista sua estreita correlação com a problemática dos gêneros do discurso. A que investimentos cenográficos convocamos os sujeitos que tomam parte no ensino de línguas? Pelo que podemos antever, tal entrada se revela de grande importância, se considerarmos que, no contexto de ensino de língua a que nos referimos, a cenografia mobilizada está muito distante da que regularmente se atualiza na sala de aula de uma instituiçấo escolar "regular". Como dito anteriormente, o tema dos investimentos cenográficos fornecerá novas bases para o trabalho com as cenas genéricas (MAINGUENEAU, 1989), reflexão que, numa ótica discursiva, nunca pode estar ausente.

A investigação dos gêneros do discurso, vistos como "tipos relativamente estáveis de enunciados" (BAKHTIN, 2011, p. 262), vem sendo acolhida como um dos marcos incontornáveis do ensino de línguas. Sua produtividade é largamente atestada, se concordarmos que se trata de importante dispositivo de economia cognitiva: ao reconhecermos que os enunciados que produzimos ou a que nos expomos constituem efetivamente um texto, isto é, ao reconhe- 
cermos que os enunciados se organizam em torno de características que o denunciam como pertencente a um determinado gênero, abreviamos a dificuldade da tarefa de compreensão e ratificamos uma certa "rede de solidariedade" entre locutores que dispóem de 'modelos textuais" (quase) coincidentes. O caminho aqui apresentado é de fundamental importância no trabalho de apropriação de uma nova língua, se considerarmos que nenhuma evidência nos garante a permanência e estabilidade de gêneros de discurso funcionando em línguas diferentes.

Contudo, em conformidade com o viés pragmático que anima a abordagem discursiva adotada (MAINGUENEAU, 1989), devemos lembrar que textos se produzem simultaneamente à produção de uma comunidade, e que esse duplo engendramento implica necessariamente uma intervenção no mundo: textos são produzidos, comunidades se constituem e açóes são executadas, com evidentes efeitos produzidos no mundo. Quando tais açóes dizem respeito ao mundo do trabalho, justifica-se, então, a formulação do conceito de "gêneros de atividade" (CLOT; FAÏTA, 2000, p. 12), espécie de memória de maneiras de pensar e de agir no trabalho, em constante processo de reequilibração e consensuada entre pares em um dado meio profissional. Da mesma forma que os gêneros dos discursos representam um elemento de economia na produção de textos, os gêneros de atividade o são em relação aos modos de agir no trabalho, uma vez que, "se fosse preciso criar, todas as vezes que agimos, cada uma de nossas atividades, o trabalho se tornaria impossível" (CLOT; FAÏTA, 2000, p. 11).

\section{A produção dos materiais}

Neste item, faremos uma análise desses dois eixos de atuação prática para a elaboração do material didático utilizado no curso: i) a realização de atividades em torno das situaçóes de uso; ii) a repercussão do contato entre as línguas bantas e portuguesa no modo de conceber o ensino/aprendizagem de língua.

Como vimos, a elaboração dos materiais didáticos para o curso de português para refugiados parte mais das expectativas dos próprios alunos do que da imposição de uma progressão gramatical baseada em elementos semânticos e sintáticos do português padrão estabelecidos pela prescrição gramatical. Para tanto, consideramos de extrema importância o trabalho com conceitos 
dinâmicos de cultura, linguagem e sociedade, não privilegiando o reforço a imagens estereotípicas de cultura brasileira.

Outra desconstrução importante, inclusive no trabalho de formação de professores voluntários para o curso, foi o desapego ao livro didático como centralidade das aulas. Sendo assim, foi preciso nos reunirmos todas as semanas para discutir o processo de ensino/aprendizagem que achávamos mais produtivo de ser investido, a fim de estimular processos de autonomia e independência relativa das orientaçóes do professor para aprender. Por isso, incentivamos a produção de atividades em grupo, de produção oral em torno de situaçóes da vida cotidiana em diferentes espaços: hospital, escola, trabalho, rua, em meios de transporte público, entre outros, para que a aula pudesse perder, pouco a pouco, seu caráter frontal e verticalizador.

Partindo do pressuposto de que "ensinar não é transferir conhecimento, mas criar as possibilidades para a sua própria produção ou a sua construção" (FREIRE, 1996, p. 52), procuramos buscar horizontalizar o processo de produção de materiais didáticos partindo mais do pedido apresentado pelos próprios participantes e menos do que se consideravam conteúdos indispensáveis às aulas de língua estrangeira a refugiados. Este é um caráter que destacamos como muito positivo de nossa proposta de curso, pois partir das expectativas dos próprios aprendizes para se formar um curso de línguas a refugiados é algo que fez uma diferença substancialmente produtiva na aprendizagem e na motivação para impulsionar a aprendizagem da língua portuguesa.

O ingresso dos alunos no curso de português não segue cronograma, pois o trabalho de acolhimento move-se pela urgência e deve ser feito a cada nova chegada de solicitantes de refúgio no Brasil, em nosso caso, no Rio de Janeiro. Sendo assim, o número de alunos é bastante variável a cada aula, o que nos levou a organizar os conteúdos discutidos nas liçôes de maneira independente, não seguindo uma sequência obrigatória. A progressão gramatical não é linear, e os conteúdos gramaticais são um pano de fundo, oriundos da própria necessidade de interação que é produzida pelo tema. Queremos dizer com isso, por exemplo, que não iniciamos o curso ou as unidades com a aprendizagem de letras do alfabeto e números, como a maioria dos livros didáticos de língua estrangeira o faz.

Os números e as letras do alfabeto são aprendidos em contextos situacionais, em que adquiram sentido de uso e que estejam em relação direta com 
as determinadas situaçóes, trabalhando não com números isolados, mas com os números das linhas de ônibus que os alunos utilizam, com os valores da passagem de transporte, o troco, entre outros contextos. Desse modo, consideramos o espaço discursivo como redes de interação semântica. Esse espaço define o que Maingueneau denomina de processo de "interincompreensão" generalizada, que estabelece a condição de diversas posições enunciativas (MAINGUENEAU, 2005, p.103).

O material elaborado não segue uma progressão gramatical linear, e cada lição, dirigida a cada aula, ao contrário, é independente das demais. Sendo assim, não é necessário que as lições sigam uma ordem pré-estabelecida, pois esta organização é delegada ao professor e advém do pedido dos alunos de temas a serem trabalhados. Do mesmo modo, os conteúdos se repetem, pois, como o fluxo de alunos é contínuo, a grade de descritores também deve ser circular, de modo que os conteúdos reapareçam em mais de uma lição. Essa grade de descritores é organizada com base nos eixos temáticos de cada unidade, sendo os quatro eixos principais: emprego e renda, mobilidade urbana, comércio e instituições públicas, histórias do Brasil.

O eixo que tematiza emprego e renda é, geralmente, o que ganha maior adesão dos alunos, pois a maioria está interessada em conhecer os procedimentos de inserção no mercado de trabalho. Essa unidade tem como objetivo discutir os meios de se procurar emprego com atividades de leitura instrumental de classificados e anúncios de empregos, atividades de produção oral e escrita, como marcar uma entrevista por telefone ou por e-mail, preparar uma carta de apresentação, currículo, além de possibilitar ao aluno o contato com situaçóes de diálogos por telefone, em situação de entrevista ou de dinâmicas de grupo.

Além disso, nessa unidade exploramos o vocabulário relativo às profissôes, tais como termos do campo do trabalho (férias, décimo terceiro, remuneração, INSS, seguro-desemprego, licença-maternidade, etc) e verbos que vão surgindo nas atividades orais e escritas elaboradas remetendo a esse campo semântico.

$\mathrm{Na}$ unidade didática intitulada "mobilidade urbana", por exemplo, são trabalhadas situaçóes comunicativas (leitura de mapas de linhas, compra de bilhetes, procedimento de embarque, códigos discursivos - assentos preferenciais, vagóes especiais para mulheres, padróes de comportamento) e discussóes, inclusive, sobre políticas públicas de acesso da população à rede de 
transportes, qualidade dos serviços, disponibilidade dos serviços, clareza e transparência das questôes relativas ao transporte em nossa cidade, bem como os investimentos que são aplicados desigualmente em zonas mais periféricas da cidade. Todas as questóes levantadas são fruto de questionamentos sobre a mobilidade na cidade que ultrapassam a mera informatividade e que respondem às expectativas trazidas pelos refugiados para a sala de aula.

Observa-se, portanto, a inviabilidade de se definirem temas a priori para serem trabalhados em sala, sob o risco de criarmos padróes de aprendizagem que culminem em "manuais" a serem seguidos, criando assim "comunidades imaginadas", parafraseando o sentido atribuído à criação das nações por Benedict Anderson (2008).

Do mesmo modo, não adotamos atividades avaliativas de rendimento aos alunos, que são incentivados a realizar autoavaliaçóes e a tomar a decisão de mudar de turma tendo como base seus instrumentos individuais de avaliação.

Acreditamos, assim, que o projeto contribui para a redução das açóes verticalizadas em sala de aula, reduzindo a distância entre participantes e professores, que, na realidade, atuam mais como mediadores da aprendizagem.

\section{O contato entre as línguas do grupo banto e a língua portuguesa}

O contato entre as línguas é um tópico bastante interessante, sobretudo porque também influenciou nossos modos de conceber o ensino/aprendizagem de língua portuguesa por meio das práticas linguageiras observadas através do contato com o outro.

Como 75\% dos alunos do curso são de origem africana e muitos vêm dos mesmos países, como Senegal, Nigéria e República Democrática do Congo, pudemos identificar algumas especificidades e preferências com relação aos métodos de aprendizagem.

Antes de abordamos tais especificidades, vale dizer que os termos "alunos", "professores" e "turmas" estão sendo utilizados em sentido metafórico, pois a proposta de elaboração de materiais didáticos e o formato das "aulas" propostos aqui não correspondem ao sentido tradicional de ensino a que os termos fazem referência. Não compartilhamos da ideia tradicional de ensino/ aprendizagem de línguas que se inscreve fundamentalmente em conteúdos definidos a priori e à revelia dos atores envolvidos nas açóes de aprendizagem. 
Tampouco concordamos com os conceitos de "aulas" ou "turmas" estabelecidos pela visão escolar da organização linear de conteúdos e percursos de aprendizagens, definidas pela compartimentação dos saberes e conhecimentos acumulados por certo grupo privilegiado, que ignora as possibilidades múltiplas, diversificadas e emergentes do contato com os grupos de "alunos".

Definidos nossos posicionamentos a respeito de nosso entendimento do que deveria ser a organização de "aulas" de línguas estrangeiras, passaremos a explicitar as especificidades do contato com os grupos com os quais atuamos. A primeira especificidade observada foi em relação ao maior interesse da turma de falantes de francês, em sua maioria congoleses, por atividades de interação oral. Conversando com alunos e alunas dessa turma, descobrimos que, na regiáo de onde vem a maioria dos alunos, os trabalhos são feitos em comunidade, em grupo, e raramente são realizados individualmente. Além da preferência pelo desenvolvimento de atividades em grupo, há também a questão da oralidade que se sobrepóe, em muitos casos, à produção escrita. Como algumas línguas maternas dos alunos não possuem escrita, são essencialmente pertencentes a culturas oralizadas, a maioria dos alunos acaba preferindo trabalhar com atividades orais a atividades escritas.

(...) as sociedades africanas serviram-se da oralidade como forma preferencial de aquisição e transmissão de conhecimentos, constituindo-se como povos de "tradição oral”. Por isso, a oralidade náo pode ser considerada um acaso da história e, qualquer que seja a causa e a consequência, ela é a manifestaçáo de uma relação com o mundo e com a funçáo de comunicação diferente das sociedades de escrita (PETTER, 2015, p. 16).

Com o conhecimento dessa demanda, passamos a adaptar o material dessas turmas para o trabalho com a oralidade em primeiro plano. Assim, antes de apresentarmos um texto escrito, ele era apresentado oralmente, por meio de atividades dinâmicas de leitura com a turma, uso de músicas, ou vídeos, por exemplo. Só depois de ouvir o texto é que este era apresentado em sua forma escrita. Percebe-se que náo abandonamos atividades com a escrita, mas investimos mais no primeiro contato com as atividades de modo oralizado. 
Outra especificidade foi observada em relação à comunicação das mulheres de determinados grupos por meio de uma língua que só elas dominam. Percebemos que o uso de determinada língua ou variante linguística relaciona-se com o papel social que representam naquela sociedade. Em alguns casos, as mulheres não se expressam na presença dos homens, o que possibilitou a criação de momentos de conversas em sala de aula sobre os direitos das mulheres no país e suas especificidades de acordo com a classe social, região do Brasil, etc. Tais aberturas para as conversas foram motivadas pelos materiais didáticos elaborados.

Logo nas primeiras aulas, percebemos que os alunos se sentiram à vontade para trazer dúvidas e fazer pedidos aos professores por determinado tema. Sendo assim, muitas perguntas diziam respeito ao uso coloquial da língua, uso de gírias, expressóes idiomáticas, modalizadores e pronúncia. Tais elementos que são próprios da linguagem oral e não são temas tão explorados em manuais e gramáticas prescritivas da língua, foram temas de aulas, explorando a dimensão comunicativa, funcional e dialógica da linguagem.

Nesse contexto, vê-se que os conteúdos idealizados pelos livros e manuais didáticos não contemplam as expectativas imediatas dos "alunos". Essa constatação nos aponta para uma necessidade urgente de investimento na redução da distância entre a idealização de aprendizagem de uma língua, que acaba privilegiando orientaçóes prescritivas e normativas, que nada têm a ver com os objetivos de aprendizagem dos grupos interessados, e a complexidade da realidade.

\section{Considerações finais}

No presente artigo, explicitamos o percurso de construção de alternativas para a acolhida a refugiados com uma premissa fundamental: a impossibilidade de considerá-los como um grupo específico de estrangeiros. Para além de uma particularização dos grupos populacionais aos quais se dirigem nossas ações, o que nos move é a necessidade de interrogar nossos próprios referenciais e arranjos institucionais.

No encontro produzido entre nossos referenciais conceituais e as discussóes oriundas da análise institucional, não nos parece possível descolar a pergunta "de que modo podemos contribuir com a acolhida a refugiados?" de uma outra, que em geral se apaga nos processos de "prestação de serviços": "de 
que forma o movimento de acolhida póe em xeque nossas práticas e a organização dos saberes em função das quais nos constituímos como 'especialistas' da linguagem"?

Desde a contextualização, que remete ao modo como o biopoder se institui e se articula na atualidade, o tema da situação do refúgio pode ser tomado como analisador, que permite colocar em análise os efeitos dos modos de governar na atualidade. Sem dúvida, ao lado dessas formas instituídas de governar, consideramos produtivo igualmente interrogar uma concepção a respeito das práticas de aprendizagem, uma dimensão política do saber uma língua e nossas práticas de extensão universitária.

A título de esclarecimento, considera-se como analisador um evento, uma contradição, um aspecto, que "permita, a partir de uma análise de decomposição do que aparecia até então como uma totalidade homogênea (uma verdade instituída), desvelar o caráter fragmentário, parcial e polifônico de toda realidade" (PAULON, 2005, p. 24).

Como vimos, o trabalho com refugiados emerge não como uma ação de natureza unidirecional - dos especialistas ao público -, mas como um campo de indagaçóes nas quais nossa própria inscrição como profissionais da linguagem precisa igualmente ser colocada em questão.

Nesse sentido, a discussão em torno da elaboração de materiais didáticos utilizados em "aulas" de língua estrangeira é uma questão que deveria pautar o andamento das "aulas" com as demandas apresentadas pelos "alunos", que são as pessoas mais indicadas para tematizar para que fim estão aprendendo a língua em questão.

Tal discussão poderia ser mais explorada no campo da formação de professores, sobretudo para que os futuros profissionais atuem nesses contextos de elaboração de material balizados pelas demandas apresentadas pelo grupo de interessados, sobretudo colocando em ação sua sensibilidade para a observação do entorno e das restriçóes e especificidades a que estão submetidos em seu campo de atuação, sejam elas de ordem física, social ou psíquica.

A discussão em torno dos conteúdos que se quer privilegiar é pouco produtiva quando não considera a complexidade da realidade e as potencialidades dos ambientes nos quais os "alunos" estão inseridos e tampouco se pautam nas memórias discursivas sobre as práticas que eles trazem consigo e (re)significam a cada contato com o outro. 
Considerando as diversas questóes levantadas ao longo deste artigo, gostaríamos, ao final, de afirmar um sentido de transformação que nos parece bastante produtivo para compreender o potencial que reside nas açóes de política linguística, a partir de sua expressão como atividade extensionista no âmbito da universidade. A transformação esperada para o tipo de trabalho que realizamos não se limita à aquisição de uma língua estrangeira, mas se encontra inspirada na possibilidade de acessar "uma micropolítica que implica o intensivo, os processos de constituiçấo de realidades, que abre o atual à pluralidade do socius e qualifica a transformação enquanto criação de possíveis" (AGUIAR; ROCHA, 2007 , p. 660). Desse ponto de vista, qualquer transformação realizada não possui uma indicação unidirecional. Ao contrário, ela nos implica.

\section{Referências}

AGAMBEN, G. O que é o contemporâneo? e outros ensaios. Trad. de Vinícius N. Honesko. Chapecó: Argos, 2010. Boitempo, 2008.

. O que resta de Auschwitz. Trad. de Selvino J. Assman. São Paulo: . Homo sacer: o poder soberano e a vida nua I. Trad. de Henrique Burigo. Belo Horizonte: Ed. UFMG, 2007.

AGUIAR, K. F; ROCHA, M. L. Micropolítica e o Exercício da Pesquisa-intervenção: Referenciais e Dispositivos em Análise. Psicologia: ciência e profissão, 2007, 27 (4): 648-663.

AMORIM, Marilia. O pesquisador e seu outro: Bakhtin nas ciências humanas. São Paulo: Musa Editora, 2004.

ANDERSON, Benedict. Comunidades imaginadas. Tradução Denise Bottman. São Paulo: Companhia das Letras, 2008.

ARANTES, Poliana Coeli Costa; DEUSDARÁ, Bruno. Português para refugiados: aliando pragmática e discurso em resposta a uma demanda concreta. Letrônica, v. 8: 45, 2015.

BAKHTIN, Mikhail. Marxismo e filosofia da linguagem. São Paulo: Hucitec, 2004.

. Estética da criação verbal. São Paulo: Martins Fontes, 2011.

CLOT, Yves; FAÏTA, Daniel. Genres et styles en analyse du travail: concepts et méthodes. Travailler, 4: 7-42, 2000. 
FOUCAULT, M. Em defesa da sociedade: curso no Collège de France (19751976). Trad. de Maria Ermantina Galvão. São Paulo: Martins Fontes, 2002.

. História da sexualidade I: a vontade de saber. Trad. de Maria Thereza da C. Albuquerque e J. A. G. Albuquerque. Rio de Janeiro: Graal, 1980.

FREIRE, Paulo. Pedagogia do oprimido. 17ª ed. Rio de Janeiro: Paz e Terra, 1987.

. Pedagogia da autonomia: saberes necessários à prática educativa. São Paulo: Paz e Terra, 1996.

GUATTARI, Félix. As três ecologias. Campinas: Papirus, 1990.

KASTRUP, V. A cognição contemporânea e a aprendizagem inventiva. In: KASTRUP, V.; TEDESCO, S.; PASSOS, E. (org). Politicas da cogniçāo. Porto Alegre: Sulina, 2008: 93-112.

KNOBLOCH, F. "Impasses no atendimento e assistência do migrante e refugiados na saúde e saúde mental”. Psicologia USP, v. 26, n. 2: 169-174, 2015.

MAINGUENEAU, Dominique. Novas Tendências em Análise do Discurso. São Paulo: Campinas: Pontes, 1989.

- Análise de textos de comunicação. Trad. Cecília P. de Souza-e-Silva e Décio Rocha. São Paulo: Cortez, 2001.

. Gênese dos discursos. Trad. Sírio Possenti. Curitiba: Criar edições, 2005.

PASSOS, E.; R. B., BARROS. A Construção do Plano da Clínica e o Conceito de Transdisciplinaridade. Psicologia: Teoria e Pesquisa, vol. 16 n. 1: 71-79, Brasília, jan-abr 2000.

PAULON, S. M. A Análise de Implicação como Ferramenta na Pesquisa-intervenção. Psicologia \& Sociedade, 17 (3): 18-25, set-dez 2005.

PETTER, Margarida. Introdução à Linguística Africana. São Paulo: Contexto, 2015.

ROCHA, Décio. Enlaçamentos enunciativos em Análise do Discurso: quando o dizer e o dito se interlegitimam. Linguagem em (Dis)curso Online, v. 11: 11-36, 2011.

ROCHA, Décio; DEUSDARÁ, Bruno. Contribuições da Análise Institucional para uma abordagem das práticas linguageiras: a noção de implicação na pesquisa de campo. Cadernos de Letras da UFF, vol. 40: 47-73, 2010.

ROCHA, Marisa Lopes da; AGUIAR, Kátia Faria. "Pesquisa-Intervenção e a Produção de Novas Análises”. Psicologia: ciência e profissão, 23 (4): 64-73, 2003.

Agradecimento à FAPERJ pela concessão de bolsa do Programa Jovem Cientista do Nosso Estado (Processo no 21.4710. Edital 06/2015). 


\title{
LANGUAGE TEACHING WITH REFUGEES: ETHICAL, POLITICAL AND CONCEPTUAL IMPLICATIONS IN TIMES OF BIOPOWER
}

\begin{abstract}
:
In this paper, we discuss ethical and political implications of Portuguese language teaching work targeting refugees in Rio de Janeiro. We assume a perspective of language enunciation based on discursive practices settled on a dialogic approach. In this context, it will be highlighted the intercultural dimension that presides over the dynamics of production of teaching materials.
\end{abstract}

KEYWORDS: refugee; language policy for Portuguese language teaching; production of teaching materials.

Recebido em: 04/06/2016 Aprovado em: 09/11/2016 